\title{
Paulo Freire está vivo no movimento da educação popular
}

Nélida Cespedes Rossel

Secretária-Geral do CEAAL (2012-2016)

\section{RESUMO}

O artigo é uma reflexão acerca da relevância da contribuição de Paulo Freire e da educação popular e sua perspectiva crítica e transformadora para o atual momento histórico de crise social, econômica, educativa e ambiental. É um ponto de vista do Conselho de Educação de Adultos da América Latina (CEAAL), que, como uma rede, articula vários processos socioeducativos, com organizações de base e outras redes. E procura modificar as situações que não permitem condições humanas e sociedades justas. A contribuição de Paulo Freire é significativa, por seu pensamento político, ético e educativo a partir da atual leitura do contexto, para daí ressignificar o sentido da educação e sua colaboração para a construção de outro mundo possível.

Palavras-chave: Educação popular. Política. Ética. Movimento social. 


\section{Paulo Freire is alive in the popular education movement}

This article is a reflection on the relevance of the contribution of Paulo Freire, and of popular education and its critical and transforming perspective for the current historical time of social, economic, educational and environmental crisis. It is a point of view of the Council for Adult Education in Latin America (CEAAL), which, as a network, coordinates several socio-educational processes, with grassroots organizations and other networks, and tries to change situations that do not allow for humane conditions and just societies. Paulo Freire's contribution is significant, due to his political, ethical and educational thinking, which starts from one's current reading of one's context, to then redefine the meaning of education and its contribution towards the construction of another possible world.

Keywords: Popular Education. Politics. Ethics. Social Movement.

\section{Paulo Freire está vivo en el movimiento de la Educación Popular}

El artículo es una reflexión acerca de la vigencia del aporte de Paulo Freire y de la Educación Popular y su perspectiva crítica y transformadora, frente a la actual crisis social, económica, educativa yambiental. Es una mirada desde el quehacer del Consejo de Educación deAdultos de América Latina (CEAAL) quecomored, articuladaa múltiples procesos socioeducativos, con organizaciones de base y otras redes, busca aportar a la construcción de las condiciones que permitan el despliegue de la condición humana y de sociedades justas. El aporte de Freire es significativo por su planteamiento político, ético y educativo, que ayuda a leer el contexto actual y darle un nuevo significado al sentido de la Educación y su colaboración a la construcción de otro mundo posible.

Palabras clave: Educación popular. Política. Ética. Movimiento social. 


\section{Introdução}

O Conselho de Educação de Adultos de América Latina (CEAAL) tem o orgulho e a responsabilidade de ter tido como seu primeiro presidente Paulo Freire, um dos mais significativos educadores do século XX. Ele continua influenciando, com seu pensamento e sua prática, nos processos de mudança de nossas sociedades, por uma educação libertadora, a favor da justiça, por democracias participativas, pela defesa irrenunciável à vida digna, especialmente dos oprimidos, e trabalhando permanentemente junto ao outro por um contexto político social, educativo, cultural, ambiental e econômico que contribua a humanizar-nos.

Sua postura ética, política e sua contribuição à educação libertadora são marcas indeléveis que continuam animando-nos e que as palavras de Nita Freire gratificam magistralmente:

Paulo nunca se cansou de repetir: sou esperançado não por obstinação, senão porque sou um ser humano, porque quero e sei que posso, junto com outros e outras, mudar o mundo para melhorá-lo e fazer realidade o sonho utópico de hoje: uma sociedade mais justa, mais bela e mais ética, em suma, mais democrática. (Freire, 2005, p. 64).

Já se quis minimizar a contribuição de Paulo Freire, que foi apelidado de passadista. Sua obra tem sido também assunto de múltiplas interpretações, como bem se explica em "Os múltiplos Paulo Freire" (Torres, 2007). Em outro caso, Freire foi mal interpretado ao asseverar que nada havia inventado e que eram as pessoas que atribuíam diversos significados à sua contribuição. A realidade é que seu enfoque ultrapassava qualquer campo temático ou programático, pois como político e pedagogo, seu compromisso o levava a dar respostas no marco do contexto político, social, cultural, educativo de seu tempo a favor da transformação pessoal e social.

Sua contribuição se coloca no sentido de estabelecer uma relação intrínseca entre educação e política, já que a educação nunca é neutra, está a favor da dominação ou da emancipação. Desenvolveu uma pedagogia crítica, em oposição a uma educação bancária. Freire expôs que conhecer o mundo é um processo coletivo e prático, que envolve diferentes formas de saber. Nesta perspectiva, o diálogo constitui não um meio, mas uma postura ética de reconhecimento do outro. Ele aponta o diálogo como uma necessidade para conhecer e transformar o mundo, ao mesmo tempo em que nos construímos como indivíduos.

Freire estava convencido de que as lutas coletivas das organizações e movimentos sociais são espaços e formas de educar, para comprometer-se e transformar a realidade até outro mundo possível.

Seu compromisso político educativo se desenvolveu em um lapso que vai dos anos setenta às primeiras décadas do século XXI. Comparto com os leitores, de maneira sucinta, uma tentativa de linha do tempo, que faz uma breve referência a diversos textos das décadas passadas na América Latina e no Caribe em relação 
às contribuições de Freire, que falam de sua vitalidade e compromisso com as pessoas e a transformação social. Concluo apresentando algumas reflexões que, a meu juízo, são centrais da colaboração de Paulo Freire à educação popular (EP).

\section{Na forma de linha do tempo: Paulo Freire vive}

\section{Os anos sessenta: a década das ideologias e o nascimento da pedagogia libertadora de Paulo Freire}

Na década de sessenta, a economia latino-americana estava desenhada para favorecer a transferência do valor de nossas economias em direção às mais desenvolvidas, à custa do empobrecimento de nossas nações. Prevalecia o injusto sistema do comércio mundial.

Este período é considerado como a década das ideologias. Os movimentos sociopolíticos adquirem cada vez maior importância na América Latina e no Caribe. A revolução cubana, de caráter socialista, expõe um novo enfoque social, político e econômico, que rompe com o modelo vigente do desenvolvimento capitalista. Isto provoca uma feroz reação do governo dos EUA, que se sente desafiado não só pela União Soviética senão também por Cuba, no marco histórico da chamada guerra fria. Desencadeia-se, então, uma contraofensiva em direção aos governos de corte socialdemocrata e socialista, como os da República Dominicana e do Chile lo governo socialista de Salvador Allende, de 1970 a 1973). Animados pela experiência revolucionária cubana de tomar o poder, alguns movimentos de esquerda empreendem a luta armada, que se propaga em vários países da região.

Neste contexto, a pedagogia libertadora de Paulo Freire propõe uma concepção emancipadora, frente a uma realidade de injustiça e desigualdade. Freire escreve A Educação como Prática da Liberdade (1967), que recolhe suas primeiras experiências como educador popular em seu país e divulga seu método psicossocial de alfabetização de adultos.

Aportará uma visão renovada e ampliada da educação de adultos, em particular da alfabetização. Ele dizia: “Minha visão da alfabetização vai além do ba, be, bi, bo, bu. Porque implica uma compreensão crítica da realidade social, política e econômica na qual está o alfabetizado" (Freire, 1970). Por isso, concebeu a alfabetização como um processo de construção de cidadania.

Outro aspecto fundamental que reconhecemos em Freire é a ligação da educação com uma concepção de mobilização social. As campanhas, como prática da liberdade, nas quais Cuba e Nicarágua se inspiraram, vão vincular o processo educacional ao de mobilização social e política.

Nessa etapa, houve alguns abusos dos enfoques de Freire. Por exemplo, alguns 
consideravam que fazer educação popular era aplicar o método de alfabetização de forma simplificada, esquecendo o caráter político-pedagógico que Freire concebia em seu método de alfabetização. Em outros casos, entendeu-se a educação popular como doutrinamento para "conscientizar" as classes majoritárias. Ambas as posturas foram objeto de críticas e reflexões posteriores.

\section{Os anos setenta entre ditaduras, crises e discurso fundacional}

Na década de setenta, impõe-se um modelo de acumulação mais excludente e de aprofundamento das relações capitalistas, com sequelas de recessão e desemprego. Intervém o Fundo Monetário Internacional (FMI) para ajustar o pagamento da enorme dívida externa. Sucedem-se numerosas crises, como a crise ecológica, a recessão e a escassez mundial de alimentos e matérias-primas, tendo sido sendo a mais espetacular a do petróleo. As ditaduras militares assolam a América Latina, gerando repressão generalizada; os movimentos sociais e populares pugnam por abrir espaços democráticos e manter ou conquistar direitos trabalhistas e civis. Ativa-se o trabalho de defesa e proteção dos direitos humanos.

Freire aprofunda-se nos estudos acerca das causas da crise (período chileno). Em Pedagogia do Oprimido (1970), analisa as condições alienantes do homem oprimido, a institucionalização e a manipulação do conhecimento, as ações culturais antagônicas, a concepção bancária da educação, assim como os mitos dos opressores, que dizem difundir a liberdade e os direitos humanos. Difundem, também, que a rebelião é um pecado perante Deus. Ao mesmo tempo, Freire empreende a busca de soluções na relação entre educação e política, com obras como Sobre a ação cultural (1970) e Extensão ou Comunicação? (1971).

Freire insiste em que o educativo encontra-se ligado à política. E, segundo Navarro Ramos, entende a política

[...] como 'a direção racional dos processos sociais'. E dado que o homem é essencialmente um ser político, a educação deverá estar dirigida ao político. Por isso o conhecimento da realidade deverá estar orientado à mudança de estruturas sendo crítica e não só conhecimento apreensivo. (Navarro, 2009, p. 3, grifo do autor).

0 próprio Freire se afirmava como político. Em uma entrevista, dizia: "0 que acontece é que fui mal interpretado, pois me identificaram como pedagogo. Mas posso te dizer que somente sou adjetivamente pedagogo, porque substantivamente sou político" (Núñez, 2007, p.9).

Freire sustenta que homens e mulheres são, acima de tudo, seres políticos, que integram uma sociedade, que requer uma forma de organização e de participação específica. Trata-se não de qualquer tipo de política, senão daquela que busca o 
bem comum, o pão e a beleza para todos e todas, em harmonia com a natureza, e que está orientada à educação dos atores organizados.

A educação das massas se faz, assim, absolutamente fundamental entre nós. Educação que, liberte a alienação, seja uma força para a mudança e para a liberdade. A opção, por tanto, está entre uma "educação" para a "domesticação" alienada e uma educação para a liberdade. "Educação" para o homem-objeto ou educação para o homem-sujeito. (Freire, 1970, p. 34, grifo do autor).

É neste sentido que entendemos que a educação para a liberdade é aquela que empodera os atores sociais para que sonhem, busquem expandir sua liberdade e construam novos referentes pessoais, sociais, políticos, culturais. É ainda a que tem o poder como um tema substantivo. E trata de questões que envolvem líderes populares, que também são parte de movimentos sociais e de organizações de base, e que são força dos movimentos sociais.

\section{Os anos oitenta, a década perdida, neoliberalismo e lutas sociais}

Nos anos oitenta, somente três países, Colômbia, Costa Rica e Venezuela, têm regimes considerados democráticos. Em Nicarágua, em El Salvador e na Guatemala se desenvolvem lutas de libertação. Em 1979, a revolução sandinista derruba a dinastia somozista e consegue o poder na Nicarágua. Em alguns países da região, ainda há governos autoritários e ditaduras militares que praticam a tortura e promovem o desaparecimento de pessoas.

A chamada Década Perdida caracterizou-se por crises econômicas compostas de dívidas externas impagáveis; grandes déficits fiscais; inflação; fuga de capitais; fortalecimento da acumulação privada; mercantilização das relações sociais; consolidação de maior mobilidade do capital, e tentativas de combinar ajustes estruturais com ações de equidade social. Os critérios neoliberais aparecem como determinantes, e o mercado é aceito como mecanismo de controle básico da economia. 0 neoliberalismo converte-se numa ideologia totalitária, que proclama o fim da história.

A experiência revolucionária da Nicarágua sandinista permitiu o impulso à educação popular junto a setores populares organizados, assim como as propostas de transformação do sistema educativo e a Cruzada da Alfabetização.

Na segunda metade dos anos 1980 e início dos anos 1990, vive-se a renovação do discurso fundacional da EP desde o seu reconhecimento da história, dos saberes e da cultura dos setores populares. Ao mesmo tempo, articulam-se processos organizativos e de mobilização dos setores populares em diversos países. Nesse contexto, 0 ascendente movimento de mulheres questiona a ausência da análise de relações de gênero nos discursos dos movimentos tanto sociais quanto políticos, e 
avança na relação entre a epistemologia feminista e a EP.

Nesse período, Paulo Freire gera novas contribuições para o desenvolvimento dos enfoques da educação popular em relação à construção de sujeitos sociais. Várias obras mostram este caminho: Que fazer: teoria e prática em educação popular (com Adriano Nogueira), em 1989; Por uma pedagogia da pergunta (com A Faundez), em 1985; Essa escola chamada vida (Com Frei Betto e R. Kostcho), também em 1985.

Nessa década também se desenvolvem algumas críticas. A primeira delas propugna que a educação popular é projeto educativo sem pedagogia, e a segunda, que é discurso político sem projeto. Em relação à primeira, questionou-se o abuso das dinâmicas e técnicas de grupo sem análise dos fundamentos e conteúdos teóricos e temáticos. Enfatizam-se a técnica e a didática, e, em vez de manter-se como meio, converte-se num fim. Em relação à segunda crítica, assinalou-se a debilidade de uma reflexão profunda sobre o contexto sócio-histórico em que os projetos são levados a cabo; também, a necessidade de contar com estruturas interpretativas da "realidade" generalizada em que vivem os grupos e que contribuem para construir projetos históricos. A respeito disso, Rosa Maria Torres assinala que "o discurso teórico vem mostrando ser pouco esclarecedor não só do seu ponto de vista, mas da sua totalidade para orientar a ação concreta" (Torres, 1988, p. 82).

\section{Nos anos noventa, muda o mapa mundial: refundamentação da EP}

Nos anos noventa, acelera-se a globalização, persiste a economia neoliberal de mercado e se produzem reformas no âmbito do Estado. Fracassam as reformas econômicas neoliberais, que não reduzem a pobreza. Mesmo tendo melhorado a macroeconomia, seus efeitos não chegam a muitos cidadãos; pelo contrário, aumenta a desigualdade e aumentam percentagens da população na economia informal. A reestruturação neoliberal se faz à custa dos pobres e excluídos.

No âmbito político, no mapa da América Latina, desapareceram as ditaduras, inclusive no Haiti, com a queda de Duvalier e a vitória de Arístide. A Frente Sandinista de Libertação Nacional (FSLN) é derrotada nas eleições da Nicarágua. Granada e Panamá são invadidos pelos EUA. A América Central entra em processo de paz e sua esquerda, antes alçada em armas, redefine sua estratégia e atua dentro dos marcos institucionais. Em todo o continente se vive um período de reinserção e adaptação.

A queda do socialismo real na Europa central em 1989 e a desintegração da União Soviética dois anos mais tarde constituem os acontecimentos mais importantes do final do século passado, pois desaparece a divisão bipolar do mundo. Com seus diferenciais e peculiaridades, a esquerda latino-americana se recompõe. Seus 
referenciais são as grandes maiorias excluídas e exploradas.

Esse período se caracteriza por uma reformulação da obra de Paulo Freire, pois este repassa seu método e leva à maioridade sua pedagogia do oprimido. Caracterizam o período os textos Pedagogia da Esperança (1992) e Pedagogia da autonomia (1996), assim como Cartas a quem pretende ensinar (1994). Neste período, Freire busca oferecer a alternativa ante o poder que ideologicamente se apresenta como o melhor.

Para a EP, os noventa é o momento da chamada refundamentação. No CEAAL se desenvolve este debate.

[...] não se tratava de uma crise de eficiência, nem sequer de capacidades pedagógicas, senão de uma recolocação do campo próprio da educação popular e de sua contribuição para a criação de maior poder para os movimentos populares [...] [que] estavam colocando as regras do debate político de uma forma diferente da que era conhecida na educação popular desde seu processo originário nos anos sessenta e setenta. $\mathrm{Ou}$ seja, que quando se colocava a importância de fortalecer a dimensão pedagógica da educação, se estava expressando a necessidade de construir um novo conceito prático do poder, e seu correlativo no campo da cultura e dos aprendizados, para exercer um poder social transformador. A meu entender, o que se queria indicar quando se manifestava a importância de fortalecer a dimensão pedagógica da educação era a necessidade de construir um novo conceito prático do poder e seu correlativo no campo da cultura dos aprendizados para exercer um poder social transformador. [...] Com a perspectiva do tempo, entendemos que a educação popular não estava "dividida" entre pedagogistas e políticos, como se dizia às vezes em eventos desses anos, senão que estavam enfrentando um desafio mais complexo que era fundar novamente sua pedagogia política. (Osorio, 2004, p. 6-7, grifo do autor).

Nesse sentido, o debate procurava superar o sentido da educação popular somente como método de organização. Tratava-se da preocupação pelo pedagógico como processo político, de aprendizado que contribuísse ao empoderamento dos atores sociais. Esse processo de debate sobre o sentido e o significado que tinha a prática da educação popular num momento diferente ao de seu nascimento serviu para afirmar os princípios que tinham dado origem àquela prática.

Passou da crise da ressignificação-refundamentação a um momento de resgate de raízes e de continuidade da ressignificação da concepção de educação popular. Assim, o processo de refundamentação tem e ganha outro sentido, porque se realiza desde uma determinada direção, desde um rumo determinado que é o compromisso histórico, ético, político e pedagógico da educação popular com a formação humana emancipadora das classes populares, com sua autonomia e protagonismo e com um projeto de futuro para a humanidade, que somente será possível com a transformação do atual. Tendo a necessidade de seguir adiante, praticando e formulando, a partir do (relafirmado. Este parece ser o grande desafio. (Paludo, 2004, p. 78). 
Neste cenário, ao oferecer conhecimentos e aprendizados significativos, a sistematização de experiências contribui estrategicamente para o avanço dos processos educativos, políticos e organizativos.

A sistematização é aquela interpretação crítica de uma ou várias experiências que, a partir de seu ordenamento e reconstrução, descobre ou explicita a lógica e o sentido do processo vivido nelas: os diversos fatores que interviram, como se relacionaram entre si e por que o fizeram dessa forma. A Sistematização de Experiências produz conhecimento e aprendizados significativos que possibilitam apropriar-se criticamente das experiências vividas (seus saberes e sentires), compreendê-las na teoria e orientálas em direção ao futuro com uma perspectiva transformadora. (Jara, 2010, p. 47).

Neste sucinto percurso, visualizamos a profunda colaboração de Paulo Freire em relação às diversas conjunturas na América Latina - e, por sua vez, as críticas aos abusos de suas concepções e algumas reflexões da refundamentação da EP. Igualmente, valorizamos Freire por sua leitura permanente dos contextos e a forma como afeta a dignidade e a humanidade de homens e mulheres, seu olhar amoroso e esperançoso da possibilidade das mudanças e de uma sociedade sem oprimidos e opressores. Freire é um convite a reaprender que a educação popular tem uma grande reserva desde sua dimensão ética, política e pedagógica.

Na dimensão ética porque ao longo de várias décadas partiu do olhar dos pobres e discriminados de nossas sociedades, de nossas comunidades. E sustentou suas reflexões e contribuições desde o olhar e os anseios dos pobres, e exigiu mais capacidade crítica e mais capacidade propositiva e proativa em seus enfoques. Nesse sentido, Freire reivindicou a utopia de uma educação para a vida, para o amor, a justiça e a solidariedade entre os homens.

$\mathrm{Na}$ dimensão política, porque em sua trajetória Freire nos ensinou que a educação nunca é neutra, que tem uma intencionalidade que envolve práticas, valores, utopias que reproduzem, legitimam, questionam ou transformam as relações de poder prevalecentes na sociedade. Uma dimensão que se sustenta em homens e mulheres que "estão sendo", inacabados, urgidos de diálogo para construir-se como pessoas e como sujeitos sociais de mudança, que se organizam de diversas formas, não só partidárias mas também em suas organizações de base e de movimentos sociais, construindo poder subjetivo, popular e democrático.

Na dimensão pedagógica, porque Freire expôs que a educação deve servir para que os educadores e educandos "aprendam a ler a realidade para escrever sua história". Isso supõe compreender criticamente seu mundo e atuar para transformá-lo em função de "inéditos viáveis". Ao redor da dita ação e reflexão e através do diálogo, os educandos e os educadores se constituem em sujeitos. 0 resto está numa reflexão profunda em volta dos processos pedagógicos que motivam a apropriação e a criação de saberes que contribuam a criar mais poder para os sujeitos que buscam uma sociedade diferente da atual. Somente este 
acúmulo de poder “subjetivo” (o poder dos sujeitos sociais) fará possível desmontar o neoliberalismo.

\section{0 século XXI de crise e de outro mundo possível}

No marco do Fórum Social Mundial temático, cujo lema foi "Crise capitalista, justiça social e ambiental", realizado em Porto Alegre, em janeiro de 2012, refletiuse sobre as consequências de um modelo de desenvolvimento capitalista, que não tem sido de crescimento e progresso. Pelo contrário, no terreno social, econômico e ambiental assistimos a profundas alterações e desigualdades:

Os ricos ficam mais ricos e os pobres mais pobres em todos os países. Ao redor de 300 pessoas bilionárias recebem o equivalente ao que recebem 2,000 milhões de pessoas, que representam $45 \%$ da população mundial. Os indivíduos que podem consumir produtos e serviços da economia global são somente 1,800 milhões; o resto da população mundial, uns 4,000 milhões, olham vitrines. Em quase 100 países pobres, a renda per capita real não aumenta faz uns 15 anos. (De Rivero, 2001).

Ao mesmo tempo, realiza-se um processo de desumanização, de instrumentalização dos seres humanos.

Os seres humanos ao invés de relacionar-se entre si cooperativamente o fazem competitivamente. 0 amor e a confiança mútua se vêm substituídos pelo comércio e 0 intercâmbio de mercadorias e como mercadorias. Os seres humanos não reconhecem no outro uma natureza humana comum: veem os outros como instrumentos para satisfazer seus interesses egoístas. A humanidade, sob a exploração do trabalho assalariado, aparece cindida, separada em duas partes que não reconhecem sua comum humanidade. (Fouce, 2012).

Essas lacerantes realidades sociais, econômicas e ambientais motivaram, nos últimos anos, uma profunda insatisfação nos setores populares e médios e provocaram protestos de diversos movimentos sociais continentais, que levantam sua indignação e apresentam propostas pela construção de outro modelo social, político e ambiental, que quebre o modelo de desenvolvimento capitalista, o qual não nos levou à suposta felicidade, senão ao contrário disso.

Simultaneamente, vimos nessa etapa a emergência de governos progressistas que, em alguns casos, lograram que milhões de pessoas saíssem da pobreza, sem quebrar com o modelo capitalista; ou outros que, assumindo-se progressistas, provocaram profundas divisões sociais e grandes danos ambientais.

A deterioração humana e ambiental, como um todo articulado, não fez mais 
do que mostrar que estamos perante um modelo de desenvolvimento que não se sustenta mais. Encontramo-nos imersos em uma crise civilizatória em que teorias e formas de nos relacionarmos e de produzir clamam por uma ética do cuidado entre nós e o planeta. Esta crise apresenta, ao mesmo tempo, outras manifestações culturais: uma forma de conhecer que divide a razão do coração, a teoria da prática, o olhar do escutar. Em síntese, trata-se de uma cultura que instrumentalizou o saber a favor do consumo.

A cultura hoje predominante é de caráter antropocêntrico. Rompeu a harmonia entre os humanos e a natureza, depredando-a, em contraposição a outra cosmocêntrica, que privilegia a reciprocidade e a harmonia com a terra. É uma cultura patriarcal, da supremacia do homem sobre a mulher, desfigurando as relações de complementaridade; é uma cultura homogênea, monocultural, que não assume a diversidade como valor, nem a interculturalidade crítica, que se baseia fundamentalmente no compromisso de lutar contra todo tipo de discriminação; é uma cultura que não valoriza as relações entre as gerações, que nos tem dividido geracionalmente e nos tem atomizado; é uma cultura do "salve-se quem puder", na qual o individualismo vai contra a construção da cidadania, da capacidade de nos cuidarmos, de nos respeitarmos, e da relação inseparável entre o eu, o tu e o nós.

No campo da educação, a defesa da educação pública nestes tempos é uma bandeira fundamental de educadores populares, intelectuais e comunidades, por estar esta educação ameaçada por políticas privatizadoras. Essas políticas vão contra o direito à educação como bem público, produto do avanço do neoliberalismo no mundo, o qual impõe suas regras e mercantiliza a educação.

\section{Considerações finais}

Em pleno século XXI, reafirmamos a vitalidade e a vigência da contribuição de Paulo Freire e a aposta pela transformação política e social que expresse a vivência de uma vida humana plena, baseada na ética e na solidariedade, que nos exponha ao desafio de assumir uma nova concepção da humanidade. E o fazemos no meio de uma profunda crise civilizatória.

Nessa nova concepção da humanidade, é fundamental o reconhecimento do valor do diverso. Isto tem a ver com a compreensão dos sujeitos principais da mudança social, anteriormente centrada nos setores populares em seu caráter de classe. Esta categoria de análise da realidade amplia-se ante a presença de milhões de pessoas excluídas, discriminadas por sua condição de gênero, etnia, condição social, geracional em nosso continente. Os trabalhos com mulheres e com populações indígenas são bons exemplos, assim como os que se realizam com setores médios empobrecidos, docentes, famílias, etc. 
Surgem novas contribuições ao desenvolvimento do pensamento social, cultural, científico. Às categorias do gênero, etnia e geracional somam-se às de classe, que permitem referências mais amplas para a compreensão e a transformação da realidade. A perspectiva de trabalho em direitos humanos, a educação intercultural, o respeito ao meio ambiente se unem na busca pela justiça e a democracia real num mundo sustentável. Esta complexa realidade exige de nós o desenvolvimento de propostas que permitam repensar as relações sociais, culturais, econômicas e ambientais. E exige de nós outros enfoques, como, por exemplo, aqueles que se originam no paradigma do "bom viver". 0 sentido do bom viver é desenvolvido pelas comunidades indígenas da América, em oposição ao "viver melhor". Baseiase no respeito a todos os seres vivos e à Mãe Terra, como uma alternativa ao modelo de desenvolvimento econômico que originou a crise econômica mundial e a mudança climática.

Em oposição ao viver melhor ocidental, impregnado pela lógica neoliberal, o bom viver propõe um modelo de vida muito mais justo para todos. 0 viver melhor do mundo ocidental se relaciona com o "viver mal" de muitos para que uns poucos vivam bem; sustenta-se na vivência da harmonia entre pessoas e no entorno natural, sem depredá-lo, vivendo-se dignamente e feliz.

Paulo Freire, desde a pedagogia critica, propôs uma ruptura epistemológica do paradigma egocêntrico e antropocêntrico da cultura ocidental. Seu pensamento questiona as relações de poder que se geraram através de situações assimétricas. Portanto, considerar a exigência ética da pedagogia crítica é reconhecer o diverso, o respeito à diferença e a superação das desigualdades como meio para a construção de um mundo melhor, como utopia do real e do concreto. Nesse sentido, assinalou Freire:

É necessário que as chamadas minorias reconheçam que no fundo elas são a maioria. 0 caminho para reconhecer-se como maioria está em trabalhar as semelhanças entre si e não somente as diferenças e assim criar uma unidade na diversidade, fora da qual não vejo como aperfeiçoar-se nem como construir uma democracia substantiva radical. (Freire, 1992, p. 185).

Outro aspecto da merecida reflexão é a construção de uma democracia substantiva, radical, na qual é preciso apostar em regimes políticos e sociais que reflitam radicalmente uma sociedade representativa, participativa, descentralizada e comunitária, com autêntico controle do cidadão sobre as autoridades. Uma democracia com uma cidadania de alta densidade. Autores como Leis (entrevista em http://www.raulleisr.com/obras-de-raul-leis.php) propuseram que a participação está intimamente ligada ao acesso, a decisões que considere a vontade dos sujeitos. É a vontade de ser menos objeto e mais sujeito.

Isso se manifesta por meio do empoderamento do cidadão, do qual nos falava Freire, numa sociedade de sujeitos sociais vivendo democraticamente. A democracia à qual aspira Freire se refere principalmente a uma nova ordem 
social e institucional que deve manifestar-se na cultura, que tem sua base no desenvolvimento dos atores sociais que apreendem o mundo para transformá-lo e na qual o ato de ensinar e aprender contribui para a formação dos cidadãos e cidadãs. Para contribuir para esta reflexão, Pedro Pontual assinalou que

A concepção de democracia que emana é fundamentalmente substantiva, portanto não se reduz a uma noção de democracia formal, mas está associada à constituição do público, desde práticas cidadãs participativas e mecanismos para isso, o que supõe construção de relações democráticas entre governos e sociedade civil em uma perspectiva de gestão democrática dos assuntos públicos. (Pontual, 2004, p. 124).

Tal concepção supõe, também, uma noção de Estado como bem de toda a sociedade, reivindicado como instrumento de câmbio.

Até aqui estou expondo que a força do pensamento de Paulo Freire em pleno século XXI nos exige maior construção da vida democrática, o que passa pelo reconhecimento e o valor de nossas culturas para superar discriminações e exclusões que vulnerem direitos e não permitam avançar-se em democracia. Implica, portanto, trabalhar pela democracia, pela cidadania e pelo poder local. Implica a incidência de políticas públicas, particularmente voltadas à educação, assim como multiculturalismo e interculturalidade, tendo em conta o específico de cada região e contexto. Supõe também pensar a educação formal e não formal como um ato dialógico que implique que educar é conhecer criticamente a realidade, é comprometer-se com a utopia de transformar a realidade, é formar sujeitos de tal mudança. Trata-se de transversalizar e reposicionar as perspectivas de gênero, de direitos humanos e ambientalistas dentro das práticas e discursos da EP, sem fragmentá-los e desde um tratamento holístico e presente tanto nas práticas educativas quanto na vida cotidiana dos centros educativos e movimentos sociais.

Este tempo nos exige avançar na construção de uma pedagogia para o poder que, como expõe Marco Raúl Mejía, deve ter em conta "o nível de desenvolvimento subjetivo no qual se encontra o grupo com o qual vai trabalhar", para poder fazer incidirem em seis âmbitos de atuação "os participantes das atividades de educação popular" (Mejía, 2009, p. 47): a) processos de individuação; b) processos de socialização; cl processos de vinculação ao público; dl participação em movimentos; el participação em projetos políticos de governo; f) participação no massivo. Tudo isso se dá como forma de superar uma visão que homogeneizou a formação dos sujeitos sociais, anteriormente criticada, e que nos ajudará, desde a vertente da pedagogia crítica, ao desenvolvimento educativo das diferentes dimensões dos sujeitos sociais para a transformação.

A contribuição de Paulo Freire à educação popular continua recriando-se desde suas bases primogênitas: al a promoção de um pensamento crítico para a análise da realidade política, social, cultural, econômica, ambiental, no sentido de avançar 
até a emancipação pessoal e social; b) a intencionalidade política emancipadora que se contextualiza: c) o reconhecimento do rol dos sujeitos populares como atores de sua emancipação; d) o entendimento dos sujeitos em suas múltiplas dimensões: racionais, afetivas, lúdicas e transcendentes; el a interatuação de processos pedagógicos com tais dimensões, para a transformação pessoal e social; fl a contribuição de metodologias e estratégias de trabalho para que os sujeitos se construam como pessoas ativas, participativas - sujeitos sociais de direitos e cidadãos contribuindo para a construção de um destino comum entre as pessoas e com a natureza.

Termino dizendo a Paulo (2006), com grande carinho e admiração, estas palavras: fique seguro, que o lembraremos conforme sua própria orientação: "Gostaria que se lembrassem de mim como um sujeito que amou as pessoas, os animais e a vida".

\section{Referências}

DE RIVERO, Oswaldo. Cap. VI La búsqueda de El Dorado. En: DE RIVERO, Oswaldo. El mito del desarrollo. Lima: FCE, 2001. Disponível em: <http://optica.machorro. net/Lecturas/mito/MitoDelDesarrollo.html>. Acesso em: 29 fev. 2012.

FOUCE, José María. La filosofía de Marx. 2. Alienación e ideología. Webdianoia. La filosofía en el bachillerato, s.f. Disponível em: <http://www.webdianoia.com/ contemporanea/marx/marx_fli_alien.htm>. Acesso em: $1{ }^{\circ}$ mar. 2012.

FREIRE, Ana María. Testimonios. Decisio, México, CREFAL, n. 10, 64-65, jan.-abr. 2005.

FREIRE, Paulo. Pedagogia del oprimido. México: Siglo XXI Editores, 1970. .Cartas a quien pretende enseñar. 2. reimp. Buenos Aires: Siglo XXI Editores Argentina, 2004.

La educación como práctica de la libertad. 2.ed. Montevideo: Editorial Tierra Nueva, 1970. Tradução direta do português Educação como prática da liberdade, por LiliánRonzonie, Prólogo de Julio Barreiro. 3. ed. Montevideo: Siglo XXI Editores, 1997.

Política y educación. Buenos Aires: Siglo XXI Editores, 1996.

. Pedagogía de la autonomía: saberes necesarios para la práctica educativa.

México : Siglo XXI Editores, 1997.

. Pedagogía de la esperanza. 1. ed. en español. México: Siglo XXI Editores, 1992.

. Pedagogía de la tolerancia. Organização e nota de Ana Maria Araújo Freire. México: FCE, CREFAL, 2006.

JARA HOLLIDAY. Oscar. Trayectos y búsquedas de la sistematización de experiencias en América Latina 1959-2010. San José: Ed. CEP Alforja, 2010

LEIS ROMERO, Raúl. Entrevista con Raúl Leis. Gente de Mente, programa de TV. 
Panamá 2011.

MEJÍA JIMENEZ, Marco Raúl. Pedagogía y aprendizajes. En: MEJÍA JIMENEZ, Marco Raúl.Educaciones y Pedagogías Críticas desde el Sur (Cartografías de la Educación Popularl. CEAAL; DVV; BMZ. Lima: 2011, p. 135-145.

NAVARRO RAMOS, Jesús Arturo. Algunas notas para acercarse al pensamiento de Paulo Freire desde la Pedagogía de la Esperanza, 2009. Disponível em: <http://www. docstoc.com/docs/42724999/Algunas-notas-para-acercarse-al-pensamiento-dePaulo-Freire>. Acesso em: 28 fev. 2012

NÚÑEZ HURTADO, Carlos. Vigencia del pensamiento de Paulo Freire. Educación de adultos y desarrollo, Bonn, DVV internacional, n. 69, 2007. Disponível em: <http:// www.iiz-dvv.de/index.php?article_id=281\&clang=3>. Acesso em: 28 fev. 2012.

OSORIO VARGAS, Jorge. Profundizando el Aporte de la Educación Populary el CEAAL en América Latina y el Caribe: Lectura del Periodo 1993-1996. La Piragua, México, CEAAL, n. 20, 7-16, 2004. También véase OSORIO VARGAS, Jorge. Subjetividad y política: ensayo histórico-memorial sobre la educación popular. Merlinescas. Humanidades, educación y política, Valparaíso, 3 ago. 2010. Disponível em: <http:// merlinescas.blogspot.com/2010_08_01_archive.html>. Acesso em: 28 fev. 2012.

PALUDO,Conceição. Educación Popular: Dialogando con Redes Latinoamericanas (2000-2003). La Piragua, México, CEAAL, n. 20, 63-79, 2004.

PONTUAL, Pedro. Educación popular y democratización de las estructuras políticas y espacios públicos. La Piragua, México, CEAAL, n. 20, 63-79, 2004.

TORRES, Rosa María. “Los múltiples Paulo Freires". Educación de adultos y desarrollo, Bonn, DVV internacional, n. 69, 2007. Disponível em: <http://www.iizdvv.de/index.php?article_id=277\&clang=3>. Acesso em: 28 fev. 2012. . Discursoy práctica de la educación popular. Quito: Centro de Investigaciones, 1988.

Recebido em março de 2012

Aprovado em julho de 2012

Nélida Céspedes Rossel, educadora peruana, é presidente do Conselho de Educação de Adultos da América Latina, e membro do Comitê Diretivo da Campanha Latino-americana pelo Direito à Educação. Coordenadora Regional de Tarefa em Ayacucho. Email: ncespedes@atarea.pe. 